The papers on the restriction endonucleases of the bacilli predict that they will be valuable tools in molecular biology and some of these predictions have already been fulfilled. It is fair to say that this volume is worth possessing for the bacilli alone.

Symposium II was entitled " Neisseria gonorrhoeae " and includes only four papers. They give very interesting reviews of physiology and metabolism with particular reference to the evolution of antibiotic resistance.

Symposium III, entitled " Genetics and molecular biology of industrial microorganisms ", includes 22 papers most of which are only two or three pages in length. It was by way of being a selection of hors d'oeuvres before the Third International GIM Symposium to be held in 1978. Interest of industrial microbiologists in the techniques of mutant isolation and genetic mapping has increased very greatly in recent years and the papers presented at this symposium cover a wide range of organisms and industrial applications. Several are concerned with secondary metabolism and antibiotic production, as would have been expected, but the genetics of alkane utilisation and of nitrogen fixation also find a place here. This is a useful collection of papers and indicates the steady advance of microbial genetics from Escherichia coli and allied bacteria to a wide range of organisms.

"Microbiology-1976" is well up to the standard of the previous volumes in the series and will be extensively used by many microbiologists.

Patricia H. Clark

\title{
Selected topics in clinical bacteriology
}

Edited by JoHN DE LouvoIs. 1976. London: Baillière Tindall. Pp. vii and 262. $£ 6 \cdot 50$.

Eight well-chosen review articles have been assembled for this volume by John de Louvois-although, disappointingly, there is nothing from his own pen. All of the themes are important, starting appropriately with a discussion by R. Freeman on the general problems in the diagnosis and management of infection in some of our most vulnerable hospital patients. As befits a leading exponent of the nitro-blue tetrazolium (NBT) test of neutrophil activity, Freeman strongly advocates the use of this test as a rapid means of detecting possible infection in a wide range of situations. He appears to obtain good results in the complex environment of the intensive care unit, but makes only passing mention of the problems created by non-specific inhibition of NBT reduction, notably in patients undergoing treatment with corticosteroids or other immunosuppressive drugs.

David Reeves and M. J. Bywaters comprehensively survey antibiotic assay procedures. They begin with a very useful summary of the pharmacokinetics of antimicrobial agents, stressing, for example, that the concentration of unbound drug in the tissues is all-important, despite the current obsession with total levels in plasma. Unfortunately this section is marred by the transposition of some figures and legends, as well as by errors relating to units and figure references in the text.

The remaining sections include a detailed review of the daunting subject of general bacterial taxonomy by L. R. Hill, and specific chapters on the bacteroides group and viridans streptococci by D. A. Leigh and G. Colman respectively. The microbiological problems associated with inhalation therapy equipment and medicinal products are also dealt with authoritatively. The book ends with an admirable, if too brief, account of the microbiology and ecology of human skin by W. C. Noble. As he rightly points out this most accessible of organs is one of those neglected most by microbiologists.

Each of the sections discusses an area of growth in clinical bacteriology; together they form a helpful and interesting book.

S. SELWYN

\section{Microbiological methods}

By C. H. Collins and Patricia M. Lyne. 1976. 4th ed. London: Butterworths. Pp. 521. $£ 9 \cdot 50$.

The scope of the 4th edition of this practical handbook has been restricted to " technical methods for the culture and identification of bacteria and fungi of importance in medicine, 
public health, veterinary practice and the food industry ". The text occupies 55 pages more and is set in a smaller typeface than the previous edition. Early chapters in the 3rd edition on the general characters and classification of micro-organisms have been omitted; in their place the authors have included throughout some of the technical methods peculiar to the United States and a greatly extended first chapter on the prevention of laboratory-acquired infection. While this reflects increasing awareness of the importance of this subject, it reproduces much of the material to be found in P.H.L.S. Monograph No. 6.

Almost the first half of the book deals in detail with the tools and mechanics of practical bacteriology - the isolation in culture, counting, and biochemical, serological and antibiotic sensitivity testing of bacteria and fungi. Four chapters deal with practical aspects of the bacteriology of food and food poisoning, sanitation control, and the microbiology of water, while the remaining two-fifths are devoted to a systematic description, based on conventional generic or species groupings, of methods for isolating and identifying micro-organisms of importance in human and veterinary medicine and public health.

This edition is like the curate's egg: full of meat and excellent in parts. Its main strength is the wealth of detailed practical information that it provides and its assessment, based on the author's personal experience or stated lack of it, of named techniques or items of equipment, supplemented by a useful appendix listing the names and addresses of suppliers. Occasionally, enthusiasm for detail could have been tempered with more discretion: 24 pages listing culture media and their suppliers reflect the complexity of modern methods of culture, but are of little practical value to the novice (who will consult this book along with the expert) when they refer, for instance, to 13 different nutrient broths for " general purposes ", or 12 basal media for blood agar, without offering any reasons for choosing one rather than another; the names of individual media are not to be found in the index. The pressure of describing practical methods in detail leads, in the final sections dealing with diseaseproducing organisms, to a lack of balance and sometimes to a sketchy indication of the importance to the patient of the organisms that may have been persuaded to grow from clinical specimens. Thus, the pneumococcus is described as " the causative organism of lobar pneumonia in man and of various other infections in man and animals including (rarely) mastitis".

There are also too many misprints and signs of hasty proof-reading for a book of this calibre. Most are trivial; some are confusing, e.g., " concentrated " hypochlorite, which is said to provide 1000 p.p.m. of available chorine, is contrasted with "strong" hypochlorite, said to provide 10000 p.p.m.; and on page 161 the reader is directed to manipulate a stopper with " the hand holding the hand holding the wire "; all detract from the book's worth.

Despite these strictures, a revised reprint could be consulted with profit and interest by any practising microbiologist.

A. C. Scotr

\section{Infective endocarditis}

Edited by D. KaYe. 1976. Baltimore, London and Tokyo: University Park Press. Pp. $\mathrm{x}$ and 272. $£ 12 \cdot 25$.

Donald Kaye and his colleagues-mostly those he worked with or works with in New York and Philadelphia-pick up the story of endocarditis where it was laid down by Andrew Kerr's monograph in 1955. First, the bad news. To invite 13 people to contribute to 260 pages is positively to cultivate the problems of multiple authorship and the book has repetition in plenty and considerable unevenness in the depth and quality of the chapters. To a large extent the retreading of ground is a product of overdivision of the subject. There are separate chapters on experimental endocarditis, pathogenesis and pathology and, despite chapters on clinical manifestations, treatment, treatment of complications, treatment of experimental endocarditis and prophylaxis, there are chapters devoted to endocarditis in drug addicts and the elderly, and to the importance of prosthetic valves and enterococci. On the other hand, although several contributors have a go at immunological processes in endocarditis, there is no systematic account of their nature, mechanisms or impact on diagnosis, treatment 